\title{
The Annual Migration Cycle of Emperor Geese in Western Alaska
}

\author{
JERRY W. HUPP, ${ }^{1,2}$ JOEL A. SCHMUTZ ${ }^{1}$ and CRAIG R. ELY ${ }^{1}$
}

(Received 18 April 2007; accepted in revised form 26 June 2007)

\begin{abstract}
Most emperor geese (Chen canagica) nest in a narrow coastal region of the Yukon-Kuskokwim Delta (YKD) in western Alaska, but their winter distribution extends more than $3000 \mathrm{~km}$ from Kodiak Island, Alaska, to the Commander Islands, Russia. We marked 53 adult female emperor geese with satellite transmitters on the YKD in 1999, 2002, and 2003 to examine whether chronology of migration or use of seasonal habitats differed among birds that wintered in different regions. Females that migrated relatively short distances $(650-1010 \mathrm{~km}$ ) between the YKD and winter sites on the south side of the Alaska Peninsula bypassed autumn staging areas on the Bering Sea coast of the Alaska Peninsula or used them for shorter periods (mean $=57$ days) than birds that made longer migrations $(1600-2640 \mathrm{~km}$ ) to the western Aleutian Islands (mean = 97 days). Alaska Peninsula migrants spent more days at winter sites (mean $=172$ days, 95\% CI: 129-214 days) than western Aleutian Island migrants (mean = 91 days, 95\% CI: 83-99 days). Birds that migrated 930-1610 km to the eastern Aleutian Islands spent intermediate intervals at fall staging (mean $=77$ days $)$ and wintering areas (mean $=108$ days, 95\% CI: 95-119 days). Return dates to the YKD did not differ among birds that wintered in different regions. Coastal staging areas on the Alaska Peninsula may be especially important in autumn to prepare Aleutian migrants physiologically for long-distance migration to winter sites, and in spring to enable emperor geese that migrate different distances to reach comparable levels of condition before nesting.
\end{abstract}

Key words: Alaska Peninsula, Aleutian Islands, Chen canagica, emperor geese, migration, satellite telemetry, YukonKuskokwim Delta

RÉSUMÉ. La plupart des oies empereurs (Chen canagica) nichent dans une étroite région côtière du delta Yukon-Kuskokwim (DYK), dans l'ouest de l'Alaska. Cependant, l'hiver, leur répartition hivernale s'étend sur plus de 3000 km, depuis l'île de Kodiak, en Alaska, jusqu'aux îles Commander, en Russie. Nous avons apposé à 53 oies empereurs femelles adultes du DYK des transmetteurs satellites en 1999, 2002 et 2003 dans le but d'examiner si la chronologie de la migration ou l'utilisation des habitats saisonniers différaient chez les oiseaux qui hivernaient dans des régions différentes. Les femelles dont la migration se faisait sur des distances assez courtes (de 650 à $1010 \mathrm{~km}$ ) entre le DYK et les lieux d'hivernage du côté sud de la péninsule de l'Alaska contournaient les haltes migratoires de la côte de la mer de Béring de la péninsule de l'Alaska ou s'en servaient pendant de plus courtes périodes (moyenne $=57$ jours) que les oiseaux dont les migrations étaient plus longues (de 1600 à $2640 \mathrm{~km}$ ) vers les îles Aléoutiennes de l'Ouest (moyenne $=97$ jours). Les migrants de la péninsule de l'Alaska passaient plus de jours aux lieux d'hivernage (moyenne = 172 jours, $95 \%$ IC : 129-214 jours) que les migrants des îles Aléoutiennes de l'Ouest (moyenne = 91 jours, 95 \% IC : 83-99 jours). Les oiseaux dont la migration se faisait de 930 à 1610 km vers les îles Aléoutiennes de l'Est passaient des intervalles intermédiaires aux haltes migratoires de l'automne (moyenne $=77$ jours) et aux aires d'hivernage (moyenne $=108$ jours, $95 \%$ IC : 95-119 jours). Les dates de retour au DYK ne différaient pas chez les oiseaux qui hivernaient dans des régions différentes. Les haltes migratoires côtières de la péninsule de l'Alaska pourraient revêtir une importance particulière à l'automne, en ce sens qu'elles permettent aux migrants des Aléoutiennes de se préparer physiologiquement à la migration de longue distance menant aux lieux d'hivernage, et le printemps, elles permettent aux oies empereurs qui migrent sur diverses distances d'atteindre des degrés de condition comparables avant la nidification.

Mots clés : péninsule de l'Alaska, îles Aléoutiennes, Chen canagica, oie empereur, migration, télémétrie par satellite, delta Yukon-Kuskokwim

Traduit pour la revue Arctic par Nicole Giguère.

\section{INTRODUCTION}

Emperor geese (Chen canagica) are unique among North American geese because most of the population spends the winter at a relatively high latitude $\left(>50^{\circ} \mathrm{N}\right)$ in a marine environment. While most North American geese exploit agricultural or freshwater habitats during winter and are herbivorous or granivorous (Baldassarre and Bolen, 2006), emperor geese primarily forage on invertebrates, marine grasses, and algae in intertidal habitats (Petersen, 1983; Petersen et al., 1994; Schmutz, 1994). Unlike geese that winter in large, contiguous regions of agricultural habitat,

\footnotetext{
${ }^{1}$ U.S. Geological Survey, Alaska Science Center, 1011 E. Tudor Road, Anchorage, Alaska 99503, USA

${ }^{2}$ Corresponding author: jhupp@usgs.gov

(C) The Arctic Institute of North America
} 


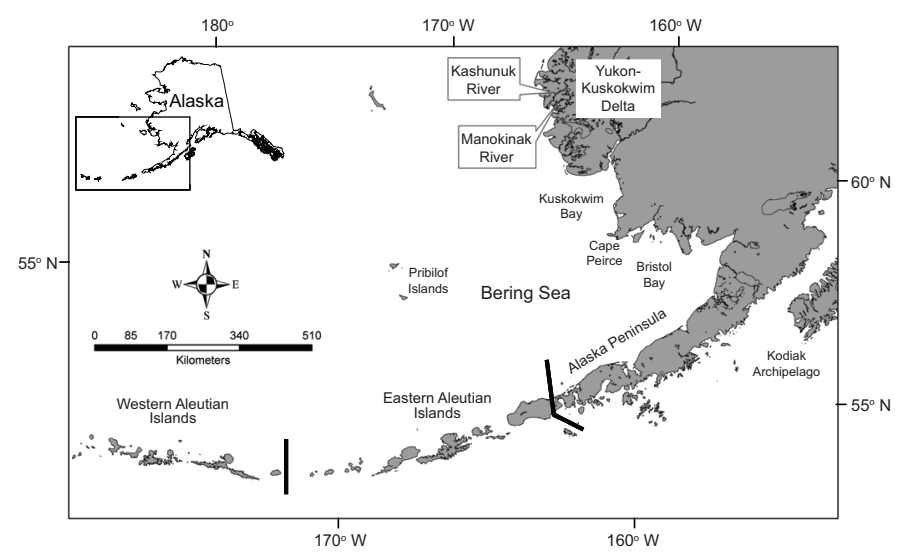

FIG. 1. Region of western Alaska where migration of adult female emperor geese marked with satellite transmitters was studied, 1999 and 2000, 2002-04. Emperor geese $(\mathrm{n}=53)$ were captured and marked at the Kashunuk and Manokinak rivers on the Yukon-Kuskokwim Delta. Black lines indicate boundaries between wintering regions. The western Aleutian Islands wintering region extends beyond the map area.

emperor geese exploit native habitats that are widely scattered in the Gulf of Alaska and Bering Sea. Their winter distribution extends approximately $3000 \mathrm{~km}$ from Kodiak Island, Alaska, west through the Aleutian Islands of Alaska and the Commander Islands of Russia. However, most of the population breeds within a relatively narrow region along the coast of the Yukon-Kuskokwim Delta (YKD) in western Alaska (Eisenhauer and Kirkpatrick, 1977; Petersen et al., 1994). Among emperor geese that nest sympatrically, some birds migrate only $650 \mathrm{~km}$ between nesting and wintering areas, whereas others migrate over $2500 \mathrm{~km}$. Migration distance affects annual energy budgets of migratory species and can have life history consequences (Alerstam and Lindström, 1990). Thus, migration strategies or use of seasonal habitats could vary among emperor geese that migrate different distances.

During much of the nonbreeding season, emperor geese occur in remote regions where harsh weather and short winter days can restrict observation. Consequently, biologists knew little about the chronology of migration, the routes emperor geese followed, or their movements during the winter months. Although coastal staging areas on the Alaska Peninsula have been described (Eisenhauer and Kirkpatrick, 1977; Petersen and Gill, 1982; Schmutz, 1994), there was little information on the duration of their use by individual birds or movements of geese among staging areas. Information on staging, winter, and migration movements of emperor geese was needed to document seasonal distribution and identify periods when important habitats were used. Protection from human perturbation is important because the population has not recovered from a more than $50 \%$ decline that occurred after the early 1960s (Petersen et al., 1994; U.S. Fish and Wildlife Service, 2005), and it remains more than $50 \%$ below management goals (Pacific Flyway Council, 2006).

Satellite telemetry has proven useful to document movements and distribution of avian migrants in remote areas. As part of a study to assess prelaying intervals in emperor geese on the YKD (Hupp et al., 2006a) and their post-breeding movements (Hupp et al., 2007a), we marked adult females with satellite transmitters. Here we examine autumn and spring migration of emperor geese, their use of migration staging areas, and their distribution and movements on winter sites. Our goals were (1) to assess whether migration chronology differed among years or was influenced by the distance that females migrated between the YKD and wintering areas, (2) to identify areas on the YKD that were used prior to autumn migration, (3) to assess whether duration of use at spring and fall staging areas on the Alaska Peninsula varied among years or differed among females that wintered in different regions, (4) to assess movements of birds among staging areas and their fidelity to staging areas between autumn and spring seasons, (5) to document migration routes between wintering and staging areas, and (6) to assess movements by emperor geese on wintering sites. This is the first study to describe the complete annual migration cycle of individually marked emperor geese.

\section{METHODS}

We captured adult female emperor geese, along with their mates and broods, during their flightless period in late July and early August in 1999, 2002, and 2003 near the Kashunuk and Manokinak rivers on the YKD (Fig. 1). We transported females from capture sites to nearby field surgical facilities, where a veterinarian surgically implanted a satellite platform transmitting terminal (PTT) transmitter (mass was $45 \mathrm{~g}$ in 1999 and $35 \mathrm{~g}$ in 2002 and 2003) in the right abdominal air sac (Korschgen et al., 1996; Hupp et al., 2006b). Transmitter antennas exited the body caudally near the base of the tail. Geese were held for at least 90 minutes to allow recovery from surgery before they were released at the capture site. Although mates and broods were released before marked females, we observed some females associated with broods within one week of release and observed most females with mates the following spring. We marked 53 females with PTTS (15 in 1999 , 20 in 2002, and 18 in 2003), deploying 34 devices at the Manokinak River site and 19 at the Kashunuk River site.

We programmed most PTTs to transmit less frequently in autumn and winter and more frequently in spring, when we wished to monitor return dates to the YKD (Hupp et al., 2006a). All PTTs in 1999 and 50\% of PTTs in 2002 were programmed to transmit signals for eight hours within each 7.3 day interval from deployment until about 15 March, whereas the remaining PTTs in 2002 transmitted four hours within each 3.9 days during those same dates. All PTTs in those years transmitted for eight hours every 3.5 days from about 15 March until 1 May, when they were programmed to begin transmitting eight hours each day. In 2003, all but three PTTs were programmed to transmit for four hours every 3.9 days from deployment until early May, when they began transmitting daily for eight hours. 
The remaining three PTTs transmitted for six hours within every 3.3-day period throughout the year.

We received data through the Argos Data Collection and Location System (Largo, Maryland). Location class (LC) was assigned following Harris et al. (1990). PTTs transmitted data on battery potential and body temperature, so we could usually determine whether the battery had failed or the female had died.

\section{Data Analysis}

We filtered PTT data via a computer program that enabled us to remove unlikely locations on the basis of the rate of movement, distance, and angle between locations (Douglas, 2006). A location was retained if it was $30 \mathrm{~km}$ or less from the previous or subsequent positions, or if the rate of movement between adjacent locations was equal to or less than $80 \mathrm{~km} /$ hour. We often obtained multiple locations for an individual during a single transmission cycle. For most analyses, we selected the location that had the highest quality to represent the bird's location within a transmission cycle. During periods when emperor geese were migrating, however, we retained all locations during a transmission cycle to examine routes used while birds were in flight.

We identified areas on the YKD that emperor geese used between capture and autumn migration because those areas may be important premigratory feeding habitats. We estimated departure date from the YKD as the midpoint between last date of detection north of Kuskokwim Bay and the first date of detection in Bristol Bay or on the Alaska Peninsula. We noted whether emperor geese used stopover sites during their migration from the YKD to autumn staging areas. Stopover sites were locations where individual birds stopped briefly (usually $<7$ days) during long-distance flights to or from staging areas. Staging areas, in contrast, were coastal lagoons on the Bering Sea coast of the Alaska Peninsula used by much of the population for extended periods ( $>30$ days) in the spring and fall (Petersen and Gill, 1982).

We determined dates of first and last detection of females on autumn staging areas of the Alaska Peninsula and noted which of the coastal lagoons they used. For females that remained on staging areas for more than two days, we noted if a female used one lagoon more than others, and if so, considered that lagoon as the female's primary staging area and other lagoons as transient staging areas. We examined direction of movement when females moved between lagoons to determine if they were using lagoons in the same order in which they encountered them while migrating to winter sites. We computed duration of autumn staging for each bird that was alive and had a functional PTT upon departure from staging areas. We noted whether females were detected at stopover sites during their migration to a winter site. A winter site was where a female primarily remained from 1 January to 15 March. For some analyses, winter sites were classified according to the region in which they occurred (Fig. 1) because birds that wintered in different regions migrated different distances and may have experienced regional differences in environmental conditions.

We examined movements of females at their winter sites. Winter locations often conformed to shoreline morphology, which resulted in a somewhat linear distribution. To assess movements, we first computed a mean location for each individual during the period it was present at its winter site. The mean was based only on high-quality (LC $=1,2$, or 3 ) daily locations that had a likely error of under $1 \mathrm{~km}$ (Harris et al., 1990). We then measured the distance between all high-quality winter locations and the central point of all locations, and expressed winter movement for each bird as the average of those distances. We computed duration of the winter period as the interval between first and last dates of detection on winter sites for females that survived the period with functional PTTs.

In the spring, we monitored movements of females and their use of stopover sites as they returned to spring staging areas on the Alaska Peninsula. We recorded the date females were first detected on the Alaska Peninsula staging areas, recorded which coastal lagoons a female used, and for those that remained on staging areas for over two days, which lagoons she primarily used. We also noted whether a female demonstrated fidelity to the same lagoon she had primarily used in the fall. We assessed movements of geese between lagoons and noted direction of movement when birds moved between areas.

Except for birds observed in flight over Bristol Bay, we estimated each female's spring departure date for the Yukon-Kuskokwim Delta as the midpoint between last detection on the Alaska Peninsula and first detection on the north coast of Bristol Bay or on the YKD. We considered that birds observed flying over Bristol Bay on a particular day had likely departed the Alaska Peninsula on that day. We noted whether females used stopover sites before arrival on the YKD. Arrival chronology and distribution on the YKD in spring has been previously discussed in Hupp et al. (2006a).

We used generalized linear models in SAS (1990) to examine variables that might have influenced migration chronology and duration of stays at staging and winter sites. We examined whether autumn departure dates from the YKD were influenced by body mass at time of capture, capture area, or year. We adjusted body mass of marked females for annual variation by subtracting the annual mean for all adult females that were marked from individual mass. We examined whether the number of days a female spent on autumn staging areas, the distance females moved in winter, or the number of days an emperor goose spent on her winter site varied among years or among birds that wintered in different regions (Fig. 1). We examined whether duration of spring staging on the Alaska Peninsula was influenced by year, region where a female wintered, or the number of days she had remained on staging areas in the fall. Finally, we contrasted the effects of year 
TABLE 1. Candidate set of linear models used to examine the effects of capture site (Mankokinak River vs. Kashunuk River), body mass at capture, and year on estimated autumn departure date of 50 adult female emperor geese marked with satellite radio transmitters from the Yukon-Kuskokwim Delta, Alaska, in 1999, 2002, and 2003. Models are ranked according to the increase in Akaike's information criterion adjusted for small sample size $\left(\mathrm{AIC}_{c}\right) . K$ is the number of parameters in the model, and Akaike weights $\left(w_{i}\right)$ are the likelihood a given model is the best among the candidate set. Departure date was invariant in the intercept (null) model.

\begin{tabular}{lcccc}
\hline \hline Model & $\mathrm{AIC}_{c}$ & $K$ & $\Delta \mathrm{AIC}_{c}$ & $w_{i}$ \\
\hline Year & 200.4 & 4 & 0.0 & 0.99 \\
Intercept & 211.5 & 2 & 11.1 & 0.004 \\
Body mass & 212.0 & 3 & 11.6 & 0.003 \\
Capture site & 213.5 & 3 & 13.1 & 0.001 \\
\hline \hline
\end{tabular}

and winter region on spring departure dates from the Alaska Peninsula. This included birds that departed from staging areas as well as those that migrated directly to the YKD from winter sites on the Alaska Peninsula.

For each analysis, we first examined a suite of candidate models that included biologically plausible combinations of the main effects and then selected the most parsimonious model from the candidate set by using Akaike's information criterion adjusted for small sample size (Burnham and Anderson, 2002). The candidate sets included a null model in which the mean of the dependent variable was invariant. We gauged relative support for models on the basis of the Akaike weight (Burnham and Anderson, 2002).

We examined whether emperor geese from the two capture areas were segregated on staging and wintering areas. We classified the primary fall and spring staging areas for each bird as northern (Egegik Bay, Ugashik Bay, and Cinder River), central (Port Heiden and Seal Islands), or southern (Nelson, Izembek, and Moffet lagoons). We used a chi-square test to examine whether emperor geese from the two different capture areas were similarly distributed among staging regions in both spring and fall. We combined staging areas into regions because expected cell frequencies were small and would have resulted in biased chi-square estimates (Zar, 1984:70) if the analysis were based on individual staging areas. We also used chi-square analysis to determine whether birds from the Manokinak and Kashunuk study areas were similarly distributed among winter regions. Failure to reject the hypotheses would indicate that emperor geese from different nesting areas became intermixed on staging and winter areas.

\section{RESULTS}

\section{Fall Migration from the $Y K D$}

Across years, PTTs provided data for an average of 283 days $(\mathrm{SD}=106$ days $)$. Of the 53 emperor geese that we

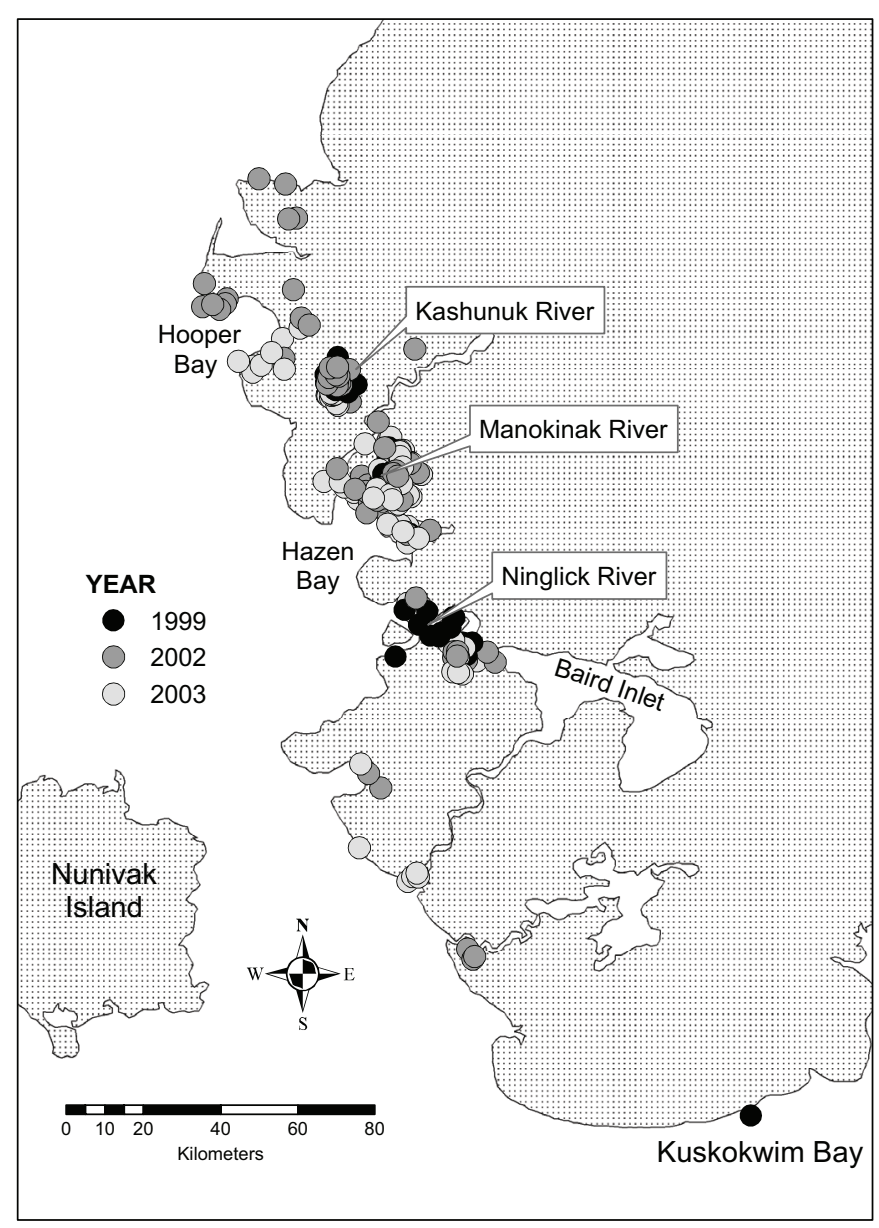

FIG. 2. Satellite telemetry locations of 50 adult female emperor geese before their autumn departure from the Yukon-Kuskokwim Delta in western Alaska in 1999, 2002, and 2003. Emperor geese were marked at brood-rearing areas on the Kashunuk and Manokinak rivers in late July and early August. High-quality locations ( $\mathrm{LC}=1,2$, or 3 ) from five days after capture until departure are indicated ( $\mathrm{n}=2-11$ locations/female). The highest-quality location during each transmission period was selected to represent a female's position.

marked with PTTs, 50 had operable transmitters upon departure from the YKD. One female died 11-18 days after capture, whereas two PTTs stopped transmitting after three to four weeks for unknown reasons.

There was strong evidence that departure date from the YKD differed among years, but little evidence that birds from different study areas migrated at different times or that body mass influenced departure from the YKD (Table 1). Median departure date was 11 September (range $=28$ Aug$25 \mathrm{Sep}$ ) in 1999, 1 September (range = 20 Aug-12 Sep) in 2002, and 31 August (range $=26$ Aug-20 Sep) in 2003 .

Emperor geese primarily remained near capture areas until their departure from the YKD. Of 283 high-quality locations for 50 females ( $\mathrm{n}=2-11$ locations/female), obtained from five days after marking until departure from the YKD, 50\% were within $3 \mathrm{~km}$ of capture sites and $75 \%$ were within $13 \mathrm{~km}$. We observed two regions of the YKD other than capture areas that were used by more than $10 \%$ of marked birds. We detected six of the 50 females in areas surrounding Hooper Bay (Fig. 2). Twenty of the females 


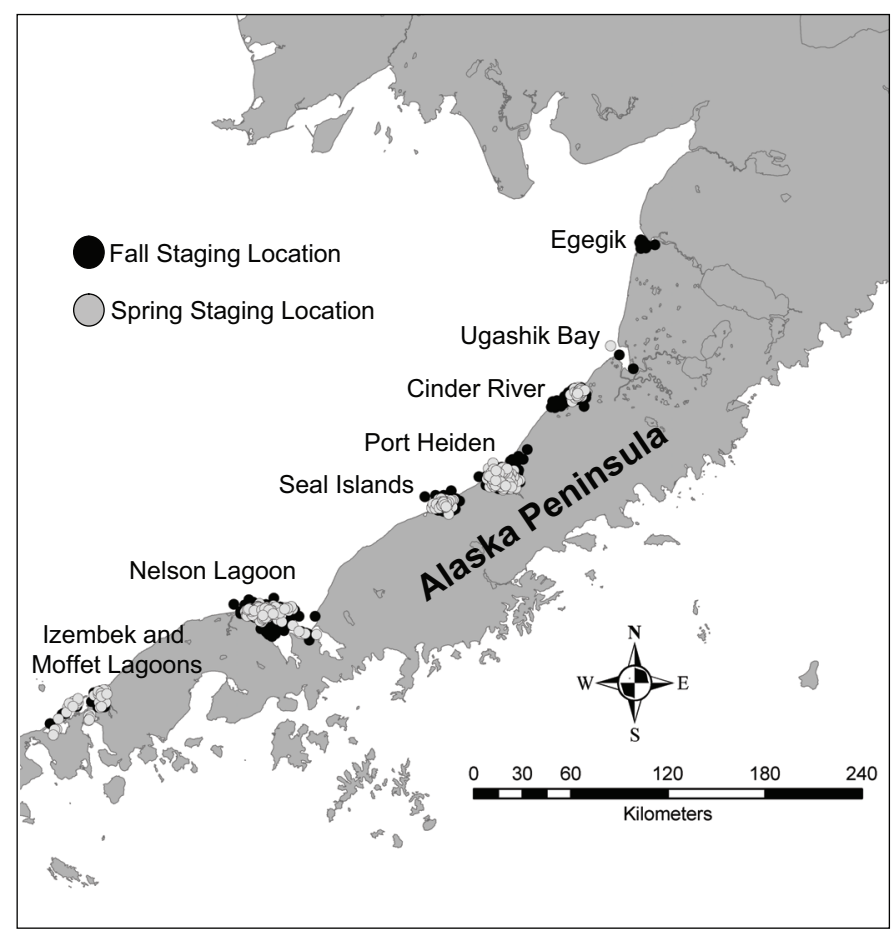

FIG. 3. Satellite telemetry locations of adult female emperor geese during autumn $(\mathrm{n}=43$ geese $)$ and spring $(\mathrm{n}=38$ geese $)$ staging on the Alaska Peninsula in 1999, 2000, and 2002-04. The highest-quality location during each transmission period was selected to represent a female's position.

(45\% of Manokinak and 29\% of Kashunuk PTTs) were detected near the mouth of Baird Inlet on the Ninglick River (Fig. 2) for periods ranging from 1 to 18 days (mean $=5.1$ days). Actual use at the Ninglick River was probably greater than observed because some females were likely present at the area when their PTTs were not transmitting.

\section{Autumn Staging on the Alaska Peninsula}

After departing the YKD, most emperor geese migrated $540-700 \mathrm{~km}$ to the Alaska Peninsula without using intermediate stopover sites. Only three of the 50 marked individuals were detected at stopover sites near Cape Peirce for 1-3 days. One female died en route from the YKD, and six females migrated directly to winter sites on the south coast of the Alaska Peninsula. Forty-three females ( $86 \%$ of marked birds) were distributed among seven lagoons on the Bering Sea coast of the Alaska Peninsula during autumn staging (Fig. 3). Birds from the two capture areas were similarly distributed among staging areas $\left(\chi^{2}=0.75,2 \mathrm{df}, p=0.69\right)$. Median date of first detection on Alaska Peninsula staging areas was 7 September (range 28 Aug-29 Sep).

Emperor geese primarily used four of the seven staging areas (Fig. 4). Although most females (56\%) were detected at more than one staging area, movement among areas was relatively infrequent. Thirty-eight females that remained on staging areas for more than two days (15-121 days) spent an average of $84 \%(\mathrm{SD}=17.8 \%)$ of their staging period at a single area. Of 40 movements among areas involving 24 individuals, $73 \%$ were from a northern
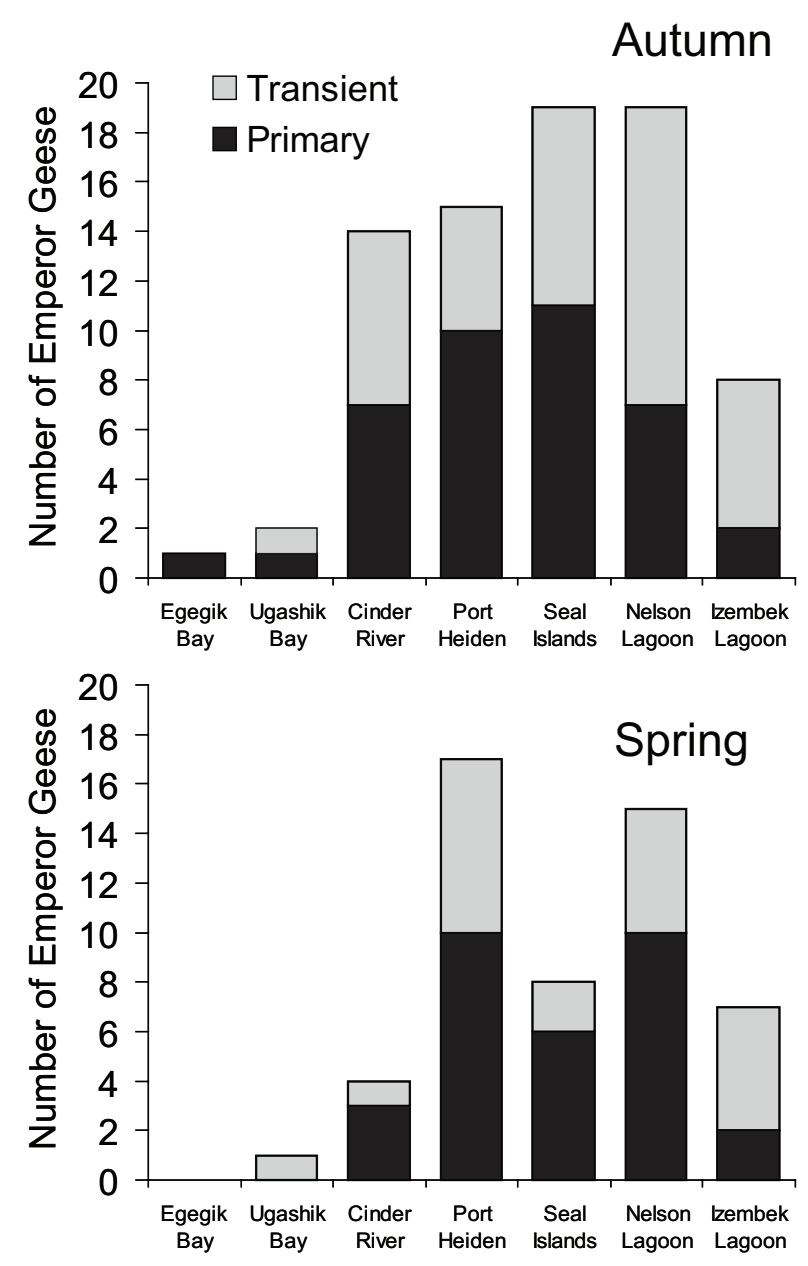

FIG. 4. Distribution of adult female emperor geese marked with satellite transmitters among coastal lagoons on the Alaska Peninsula during staging in autumn ( $n=42$ geese $)$ and spring $(n=33$ geese) of 1999, 2000, and 2002-04. A lagoon was considered as the primary staging area of a goose if the bird spent more days there than at other lagoons. Birds detected at a lagoon that had staged primarily at a different lagoon were considered transients. Only females that remained on staging areas more than two days and survived a staging interval with operable satellite transmitters are indicated. Birds observed at Moffet Lagoon are included in the total for Izembek Lagoon.

staging area to a more southern one. Of the north-to-south movements, $48 \%$ occurred during arrival on the Alaska Peninsula, when birds stopped at a northern lagoon before migrating to their primary staging site, and $52 \%$ occurred during the latter part of staging, after birds departed their primary staging area. Consequently, use of Cinder River and Seal Islands was highest during the early part of staging, whereas Nelson, Izembek, and Moffet lagoons were more heavily used during the latter part of staging.

The 42 emperor geese that survived with functional PTTs throughout autumn staging remained on the Alaska Peninsula staging areas for one to 126 days. The most parsimonious model explaining variation in length of autumn staging indicated that duration of staging was influenced by the region where a female wintered and varied among years (Table 2). After accounting for annual differences, duration of autumn staging was shorter for females that migrated to wintering areas on the south side of the 
TABLE 2. Candidate set of linear models used to examine the effects of year and winter region (Alaska Peninsula, eastern Aleutian Islands, western Aleutian Islands) on migration chronology and movements of emperor geese: (a) duration of autumn staging on the Alaska Peninsula, (b) distance moved in winter, (c) number of days on winter site, and (d) date of spring departure from Alaska Peninsula to the YKD. Data were collected from satellite radio transmitters deployed on adult female geese on the YKD in 1999, 2002, and 2003. Models are ranked according to the increase in $\mathrm{AIC}_{c}$ (see Table 1). Response variables were invariant in the intercept models.

\begin{tabular}{|c|c|c|c|c|}
\hline Model & $\mathrm{AIC}_{c}$ & $K$ & $\Delta \mathrm{AIC}_{c}$ & $w_{i}$ \\
\hline \multicolumn{5}{|c|}{ a) Duration of autumn staging $(n=42)$} \\
\hline Year + Winter region & 290.6 & 6 & 0.0 & 0.61 \\
\hline Winter region & 291.7 & 4 & 1.1 & 0.35 \\
\hline Year & 296.6 & 4 & 6.1 & 0.03 \\
\hline Intercept & 300.3 & 2 & 9.8 & 0.005 \\
\hline \multicolumn{5}{|c|}{ b) Distance moved during winter $(\mathrm{n}=41)$} \\
\hline Intercept & 160.8 & 2 & 0.0 & 0.71 \\
\hline Winter region & 163.7 & 4 & 2.8 & 0.17 \\
\hline Year & 164.7 & 4 & 3.9 & 0.10 \\
\hline Year + Winter region & 167.9 & 6 & 7.1 & 0.02 \\
\hline \multicolumn{5}{|c|}{ c ) Number of days on winter site $(n=41)$} \\
\hline Winter region & 298.8 & 4 & 0.0 & 0.76 \\
\hline Year + Winter region & 301.1 & 6 & 2.3 & 0.24 \\
\hline Year & 319.8 & 4 & $21.1<$ & $<0.001$ \\
\hline Intercept & 322.0 & 2 & $23.2<$ & $<0.001$ \\
\hline \multicolumn{5}{|c|}{ d) Spring departure date from the Alaska Peninsula $(n=36)$} \\
\hline Year & 82.0 & 4 & 0.0 & 0.88 \\
\hline Year + Winter region & 86.1 & 6 & 4.0 & 0.12 \\
\hline Intercept & 99.5 & 2 & 17.5 & $<0.001$ \\
\hline Winter region & 104.2 & 4 & $22.1<$ & $<0.001$ \\
\hline
\end{tabular}

Alaska Peninsula (least squares mean $=57$ days) than for females that migrated to the eastern (least squares mean $=$ 77 days) or western Aleutian Islands (least squares mean = 97 days). Individual variability in duration of staging (Fig. 5) was considerably lower for western Aleutian migrants (range $=56$ days) than for birds that wintered in the eastern Aleutian Islands (range $=110$ days) or on the Alaska Peninsula (range $=124$ days). Median dates of last detection on staging areas were 23 October, 30 November, and 15 December for migrants to the Alaska Peninsula, eastern Aleutians, and western Aleutians, respectively (Fig. 6). After removing the effect of winter region, the least squares mean duration of autumn staging was 60 days in 1999, 84 days in 2002, and 87 days in 2003. Use of Alaska Peninsula staging areas peaked in mid-September, remained fairly steady until mid-November, and then declined until all birds had departed by early January.

\section{Migration to Winter Sites}

Migration distances from staging to wintering areas ranged from 60 to $385 \mathrm{~km}$ for females that wintered on the Alaska Peninsula, from 113 to $696 \mathrm{~km}$ for those in the eastern Aleutian Islands, and from 870 to $1823 \mathrm{~km}$ for females that wintered in the western Aleutian Islands. Of 21 emperor geese that migrated to winter sites in the western Aleutian Islands, we observed five that stopped at

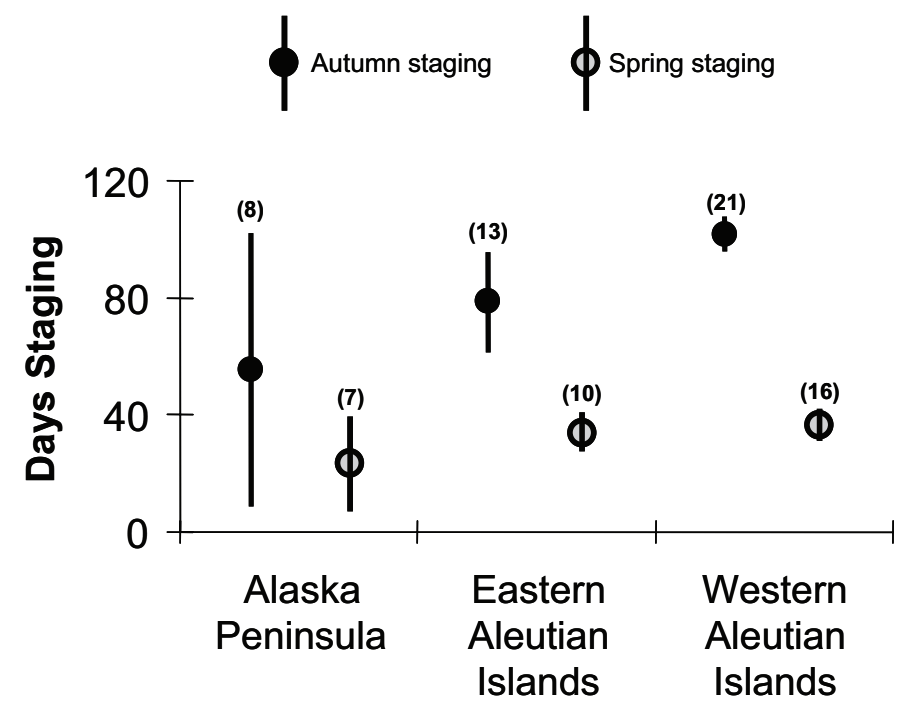

FIG. 5. Number of days that emperor geese marked with satellite transmitters remained at staging areas on the Alaska Peninsula in autumn $(n=42$ geese $)$ and spring $(n=33$ geese), relative to where birds wintered in 1999,2000 , and $2002-$ 04. Circles indicate mean estimates and vertical lines represent $95 \%$ confidence intervals. Parentheses indicate number of birds observed from each winter site in a season. Estimates are based only on females that survived a staging interval with operable satellite transmitters.

one of the intermediate islands between the Alaska Peninsula and their wintering site, indicating those individuals likely migrated along the island chain. Most (4) were detected at intermediate stopover sites for only one to two days, although one individual remained at a stopover site for 13 days. We received locations from four emperor geese that were $70-360 \mathrm{~km}$ from nearest land during their migration to the western Aleutian Islands, suggesting those birds used more direct oceanic routes. Initial locations for the four offshore birds were at night, and absence of movement for two to four hours suggests birds were roosting at sea. After remaining in approximately the same location for three hours, one of the offshore females initiated a $95 \mathrm{~km}$ movement five hours before sunrise on a night with a nearly full moon. Another offshore female remained in the same area for two hours on a moonless night and initiated a $200 \mathrm{~km}$ flight at sunrise. We received multiple offshore locations for the remaining two females during periods of two to four hours before sunrise, but during those intervals detected no movement. Their transmission cycles ended before we could assess daylight movements. We are uncertain of the migration route used by 11 females because they were not observed in transit between staging and wintering areas. However, those birds were observed in the western Aleutians during the first transmission cycle three to seven days after their last location on the Alaska Peninsula, indicating a rapid migration to wintering areas.

Of the 13 females that migrated to wintering areas in the eastern Aleutian Islands, four used intermediate stopovers for one to 18 days. The only eastern Aleutian migrant observed in flight was $10 \mathrm{~km}$ or less from nearest land. That individual migrated $90 \mathrm{~km}$ from 1.5 hours before 

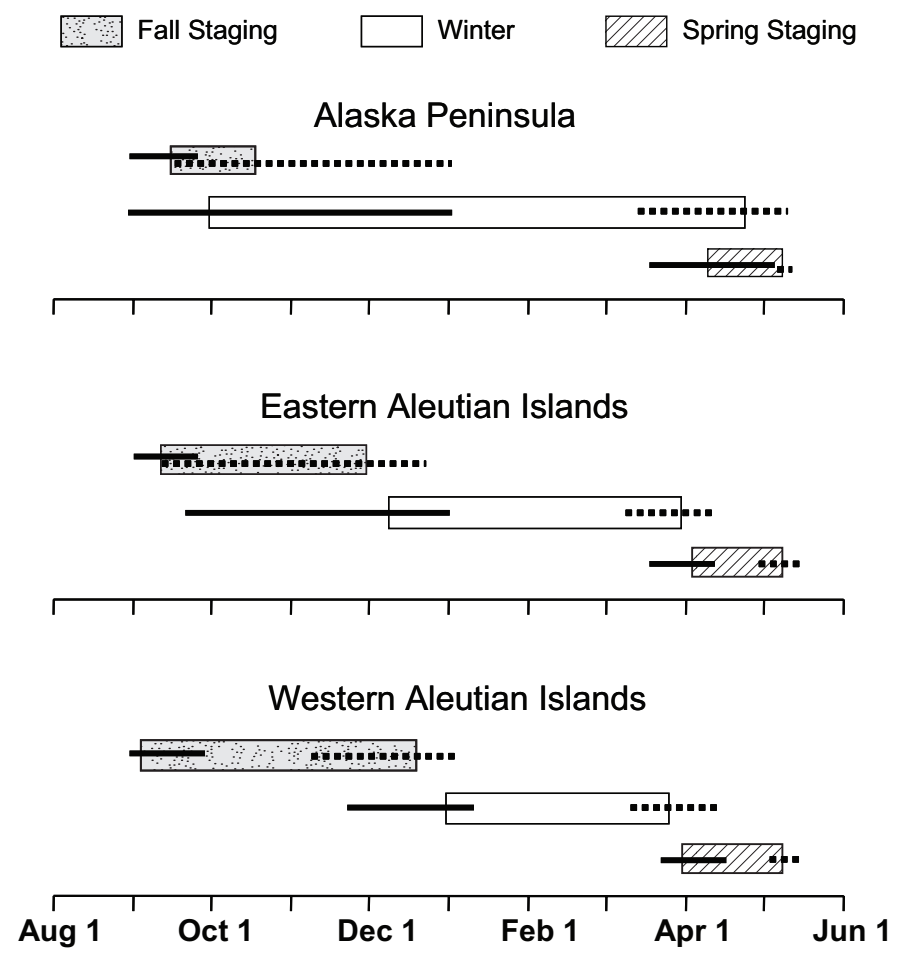

FIG. 6. Chronology of autumn and spring staging and winter intervals for adult female emperor geese marked with satellite transmitters that wintered in different regions of western Alaska in 1999, 2000, and 2002-04. Horizontal boxes indicate median intervals of use at staging and wintering areas, and lines show the ranges of individual arrivals (solid lines) and departures (dashed lines). Estimates are based on birds that survived a staging or winter period with functional transmitters. Median staging and winter intervals overlap for females that wintered on the Alaska Peninsula because some birds bypassed staging areas.

sunset until 1.5 hours after sunset, but during the final two hours of the transmission cycle moved little and remained at a location approximately $10 \mathrm{~km}$ from nearest land.

\section{Winter Distribution, Duration, and Movements}

We identified winter locations of 48 females with PTTs. Fourteen (29\%) wintered on the south coast of the Alaska Peninsula, whereas $13(27 \%)$ and $21(44 \%)$ wintered in the eastern and western Aleutian Islands, respectively (Fig. 7). Distribution among winter regions was not influenced by whether a female was captured at the Manokinak or Kashunuk study area $\left(\chi^{2}=1.3,2 \mathrm{df}, p=0.5\right)$. Median dates emperor geese were first detected on winter sites were 28 September, 8 December, and 26 December for Alaska Peninsula, eastern Aleutian, and western Aleutian migrants, respectively (Fig. 6).

Emperor geese were sedentary at winter sites. Most emperor geese in the Aleutian Islands remained on a single island throughout the winter period. Of 30 females in the Aleutian Islands whose PTTs operated throughout winter, only one moved approximately $50 \mathrm{~km}$ between islands in late February. Females that wintered on the south side of the Alaska Peninsula generally remained in a single embayment, although two of 11 females moved $60-70 \mathrm{~km}$ between different areas. We estimated total winter move-

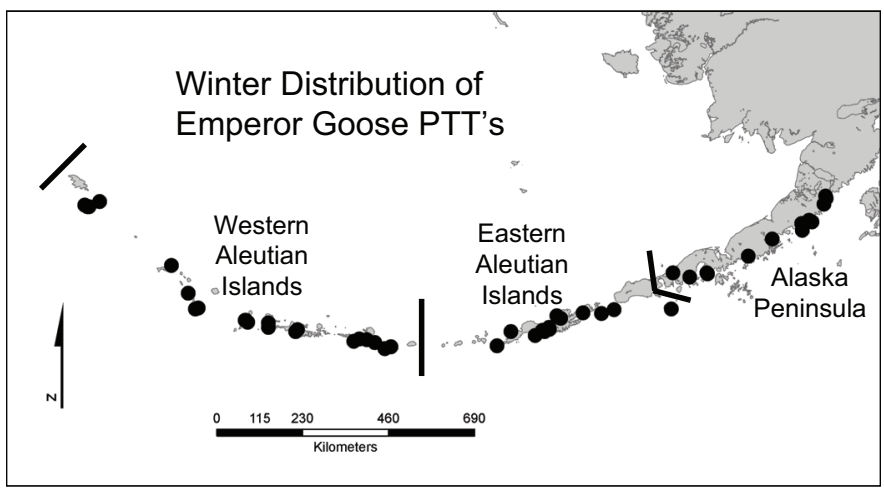

FIG. 7. Winter distribution of 48 adult female emperor geese that were marked with satellite transmitters on the Yukon-Kuskokwim Delta, Alaska, in 1999, 2000, and 2002-04. Each circle represents the site primarily used by a goose from 1 January to 15 March. Black lines show boundaries between winter regions.

ment from an average of $19(\mathrm{SD}=9.0)$ locations per female. The 41 females that survived the winter with active radios remained within an average of $4.8 \mathrm{~km}(95 \%$ CI: $2.7-10.3 \mathrm{~km}$ ) of their mean winter location. Winter movement was relatively invariant among regions and years, although there was weak evidence of a regional difference (Table 2). The regional difference was slight: females on the Alaska Peninsula remained within an average of $6.8 \mathrm{~km}(\mathrm{SD}=7.4)$ of their mean winter locations, whereas females in the eastern and western Aleutian Islands remained within $5.4 \mathrm{~km}(\mathrm{SD}=7.6)$ and $3.4 \mathrm{~km}(\mathrm{SD}$ $=6.0$ ) of mean locations, respectively. PTT locations were typically along shorelines or in nearshore areas, indicating that birds exploited intertidal habitats.

There was strong support for a model in which the number of days spent at winter sites differed among regions, but little evidence that duration of winter stays varied annually (Table 2). Average duration of the winter period for females on the Alaska Peninsula was 172 days (95\% CI: 129-214 days), substantially longer but more variable than for females that wintered in the eastern Aleutian Islands (mean $=108$ days, 95\% CI: 95-120 days) or western Aleutian Islands (mean $=91$ days, 95\% CI: 83-99 days). Median dates of last detection of migrants on the winter sites were 23 April for the Alaska Peninsula, 30 March for the eastern Aleutians, and 23 March for the western Aleutians (Fig. 6).

\section{Migration from Winter Sites}

Only five of the 31 females that migrated from winter sites in the Aleutian Islands were detected at intermediate stopover sites prior to their arrival on the Alaska Peninsula. Each used a single island stopover for one to four days. We monitored movements of five females as they were in flight during transmission cycles of four to six hours. Two females that had wintered in the western Aleutian Islands were observed migrating 80-200 km from the nearest island. Three females that had wintered at more central or eastern Aleutian locations were detected migrating along the island chain less than $30 \mathrm{~km}$ from the 
nearest island. All observations were during diurnal periods, and we observed no evidence of roosting at sea. Among females not observed in transit, last detection on Aleutian wintering areas and first detection on the Alaska Peninsula were separated by a median of four days (range $=3-21$ days). Longer intervals were for females whose locations during a transmission period were not determined (i.e., missed PTT transmissions).

\section{Spring Staging on the Alaska Peninsula}

Of the 41 females with PTTs that departed winter sites, $38(93 \%)$ were detected at spring staging areas on the Bering Sea coast of the Alaska Peninsula (Fig. 3). Three of 10 females that survived winter on the south side of the Alaska Peninsula with functional PTTs bypassed coastal staging areas and migrated directly to the YKD. Median first detection dates on staging areas were 11 April, 3 April, and 30 March for Alaska Peninsula, eastern Aleutian, and western Aleutian migrants, respectively (Fig. 6).

The 31 females that remained more than two days on staging areas (18-45 days) spent an average of $91 \%$ (SD $=15.8)$ of the staging period at a single area. Fourteen (42\%) females used more than one staging area. Of 26 movements between areas involving those 14 females, $77 \%$ were from a southern staging area to a more northern one. These were birds that stopped at Izembek or Nelson lagoons upon arrival on the Alaska Peninsula before moving to their more northern primary staging area, or stopped briefly at a northern lagoon after departing their primary, more southern staging site. Among 30 females that remained on staging areas more than two days in both spring and fall, 57\% used the same primary staging area in each season. Emperor geese used the three most northern staging areas, as well as the Seal Islands, less in spring than in the fall (Fig. 4). Geese from different capture areas were similarly distributed among spring staging areas $\left(\chi^{2}=\right.$ 0.33, $2 \mathrm{df}, p=0.84$ ).

Thirty-three females with active PTTs survived the spring staging period on the Alaska Peninsula. The most parsimonious model for duration of staging (Table 3) indicated that the number of days a female remained on staging areas in the spring increased approximately 0.2 days $(\mathrm{SE}=0.05)$ for each day on which that bird had used staging areas in the fall $\left(r^{2}=0.4\right)$. However there was substantial variability in the relationship, and it was strongly influenced by a small number of birds that had bypassed staging areas in the fall and remained three days or less in the spring. There was also some support for an effect of winter location on duration of spring staging, but little evidence of annual variation (Table 3). Females that wintered on the Alaska Peninsula spent an average of 23 days on spring staging areas, although there was much individual variation (95\% CI: 7.2-39.1). Females that wintered in the eastern or western Aleutian Islands remained on spring staging areas an average of 34 (95\% CI: $29.5-$ 38.0) and 36 (95\% CI: 32.7-39.7) days, respectively (Fig. 5).
TABLE 3. Candidate set of linear models used to examine the effects of year, winter region (Alaska Peninsula, eastern Aleutian Islands, western Aleutian Islands), and duration of fall staging on the number of days 33 adult female emperor geese marked with satellite transmitters remained on spring staging areas on the Alaska Peninsula, 2000, 2003, and 2004. (Model ranking as in Tables 1 and 2.)

\begin{tabular}{lcccc}
\hline \hline Model & $\mathrm{AIC}_{c}$ & $K$ & $\Delta \mathrm{AIC}_{c}$ & $w_{i}$ \\
\hline Days of fall staging & 147.2 & 3 & 0.0 & 0.71 \\
Winter region + Days of fall staging & 149.6 & 5 & 2.4 & 0.22 \\
Year + Days of fall staging & 152.0 & 5 & 4.8 & 0.06 \\
Winter region & 155.4 & 4 & 8.2 & 0.02 \\
Intercept & 159.1 & 2 & 11.9 & 0.002 \\
Year + Winter region & 160.4 & 6 & 13.2 & 0.001 \\
Year & 163.1 & 4 & 16.0 & $<0.001$ \\
\hline \hline
\end{tabular}

\section{Migration to the Yukon-Kuskokwim Delta}

There was strong evidence that the departure date of 36 females from the Alaska Peninsula staging and wintering areas differed among years, but little evidence that migration date differed among birds from different winter regions (Table 2). Median departure in 2000 (11 May) was later than in 2003 (6 May) and 2004 (4 May). We received 206 locations from 22 females as they were in flight during migration to the Yukon-Kuskokwim Delta. Most migrated approximately $200-275 \mathrm{~km}$ across Bristol Bay from the Alaska Peninsula and then followed the coast of the $\mathrm{Yu}$ kon-Kuskokwim Delta to their nesting areas (Fig. 8). Only four geese were detected at intermediate stopover sites before arrival on the Yukon-Kuskokwim Delta; all were along the north coast of Bristol Bay and none remained more than two days. First detection on the YKD occurred a median of 1 day (range 1-8 days) after last detection on the Alaska Peninsula. Longer intervals were from birds whose PTTs did not transition to daily transmission as programmed.

\section{DISCUSSION}

Departure date of emperor geese from the YKD in autumn was likely partially influenced by the time required for juveniles to reach adequate size for migration, and for both adults and juveniles to become physiologically prepared for fall migration. Among juveniles, survival between fledging and fall staging is positively influenced by premigratory body mass (Schmutz, 1993). Although median departure date varied among years by approximately 12 days, it was fairly invariant relative to the date when juvenile emperor geese had hatched earlier in the summer. Across years, median departure occurred $73-77$ days after the peak hatch date of emperor geese at the Kashunuk River study area (Ely and Terenzi, 2003), or approximately two to three weeks after goslings would have fledged (Petersen et al., 1994). Later departure of 


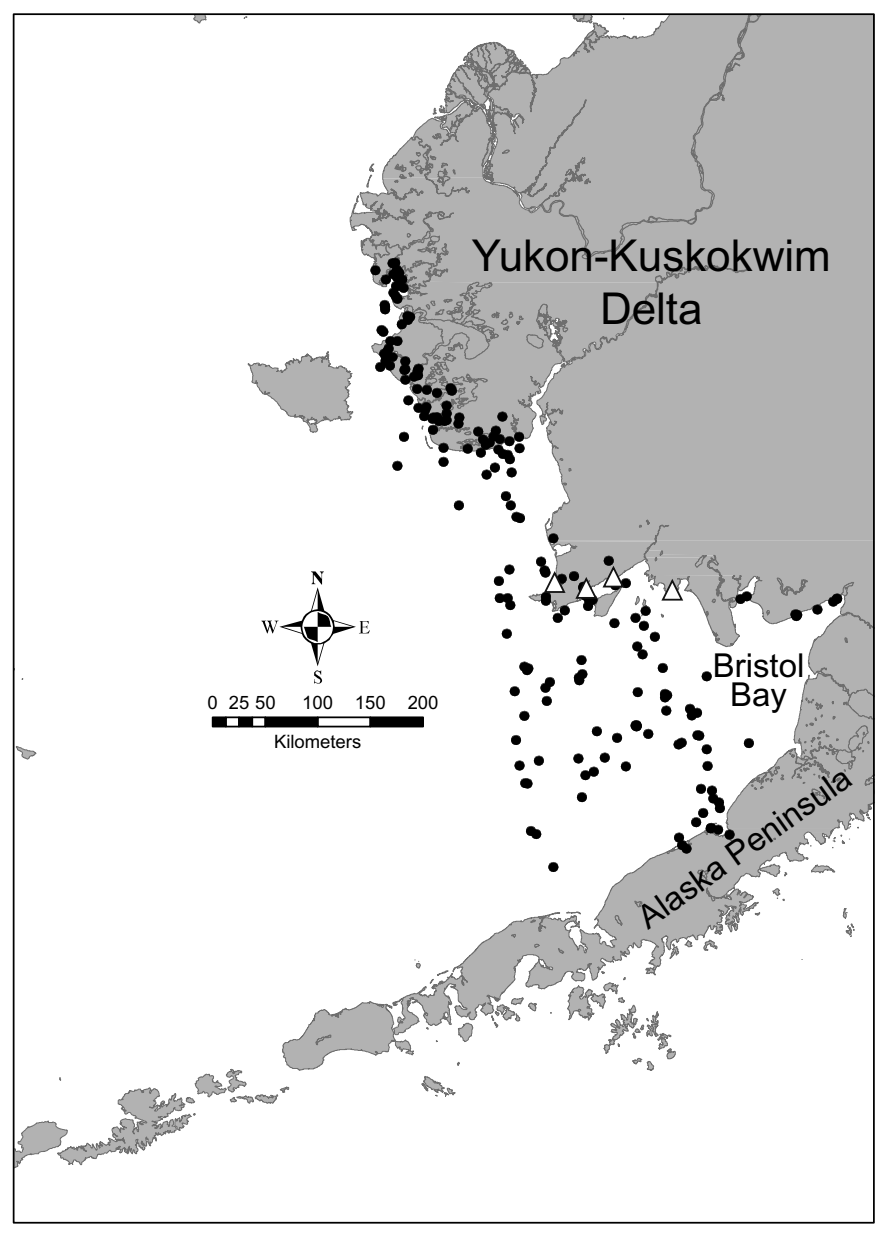

FIG. 8. Satellite telemetry locations of 22 adult female emperor geese as they migrated from the Alaska Peninsula to nesting areas on the Yukon-Kuskokwim Delta, Alaska, in spring of 2000, 2003, and 2004. Triangles indicate sites where four emperor geese used migration stopovers for one to two days.

emperor geese in 1999 may have occurred because peak hatch was six to eight days later than in 2002 and 2003 (Ely and Terenzi, 2003). Emperor geese primarily remained near their capture sites before migration, even though most birds likely had become capable of flight by the second week of August. This suggests premigratory reserves were largely acquired near brood-rearing areas. However, the mouth of the Ninglick River could have been an important stopover for some emperor geese after they left the broodrearing area but before they departed the YKD. Many of the high-quality locations at the Ninglick River were in or within $1 \mathrm{~km}$ of intertidal areas. It may have been in such areas that emperor geese made the transition from a completely herbivorous diet to one that includes marine invertebrates. Physiological condition of emperor geese may be especially important upon their departure from the YKD because most birds did not use stopover sites during their migration to the Alaska Peninsula.

Emperor geese used the same fall staging areas on the Alaska Peninsula described by Eisenhauer and Kirkpatrick (1977) and Petersen and Gill (1982). Emperor geese from different nesting areas became intermixed on fall staging areas, and they remained so during winter and spring staging. Duration of fall staging was related to distance that females migrated to winter sites. On average, females that migrated short distances to the south side of the Alaska Peninsula spent $40 \%$ fewer days on staging areas than those that typically migrated over $1000 \mathrm{~km}$ farther to winter sites in the western Aleutian Islands. Likewise, eastern Aleutian migrants spent less time on the Alaska Peninsula than those that migrated greater distances to the western Aleutians. Duration of staging became increasingly less variable among individuals with greater migration distance. Emperor geese that had shorter migrations and lower migration costs likely had greater individual flexibility in timing of their migration and use of staging areas. Emperor geese that migrated to the western Aleutian Islands likely needed to remain on staging areas until they had adequate reserves to complete long-distance flights.

Ice on coastal lagoons may limit foraging opportunities in late fall and influence departure dates from staging areas (Petersen and Gill, 1982). Earlier departure of emperor geese in 1999 was likely due to colder temperatures than in 2002 and 2003. From 1 November to 31 December 1999, there were 46 days with subfreezing temperatures at Port Heiden, compared to 15 such days during the same interval in 2002 and 35 days in 2003 (National Climatic Data Center, 2006). Wind direction and speed affect departure dates of Pacific black brant (Branta bernicla nigricans) from staging areas on the Alaska Peninsula (Dau, 1992) and may influence timing of migration by emperor geese. We observed that Aleutian migrants were less apt to depart staging areas when there were headwinds from the southwest, and that wind speeds during migration intervals were slower than during periods of nonmigration (Hupp et al., 2007b). Thus emperor geese may avoid migration at times when approaching low-pressure systems in the Bering Sea result in strong southwesterly headwinds.

Emperor geese minimized their time in migration to winter sites by migrating quickly and using few stopovers. Some birds migrated far offshore and apparently followed oceanic migration routes, which reduced the distance traveled to winter sites by up to $200 \mathrm{~km}$. Rapid migration to winter sites was likely advantageous in a region where short day length and severe weather could constrain suitable windows for migration in late fall. We observed evidence that at night some oceanic migrants roosted at sea. Thus migration may have occurred primarily during daylight hours, unless there was adequate moonlight. Although potential stopover sites were available along the Aleutian Islands, many emperor geese may have bypassed those sites because suitable intertidal foraging habitat was limited and potential for competition with conspecifics for use of those areas was high. Furthermore, intertidal foraging is constrained by tides (Schmutz, 1994), which would limit the rate at which emperor geese could replenish reserves during migration. Birds that minimize time in migration do so by developing large energetic reserves prior to migration (Blem, 1976; Alerstam and Lindström, 1990). Reserves acquired on Alaska Peninsula staging areas likely enabled emperor geese to 
adopt a strategy in which they migrated to winter sites quickly and bypassed potential stopovers. Black brant likewise have a prolonged staging period on the Alaska Peninsula (Reed et al., 1989), during which they acquire energetic reserves before embarking on a nonstop flight to southern winter areas (Dau, 1992).

Wintering emperor geese moved little, generally remaining at a single site throughout winter. Waterfowl that winter in intertidal habitats often move relatively little and demonstrate strong philopatry when returning to winter sites (Robertson and Cooke, 1999). Intertidal habitats likely provided a relatively consistent environment, in which emperor geese could satisfy forage requirements within short distances. In contrast, harvest and plowing of agricultural fields, freezing conditions, and snowfall may require geese that use agricultural and freshwater habitats to move greater distances and to shift wintering areas when conditions dictate (Frederick and Klaas, 1982; Hestbeck et al., 1991). Furthermore, hunting may contribute to movement of geese (Madsen, 1998; Béchet et al., 2003); however, for emperor geese there is no legal harvest, and often only a sparse human population on wintering areas.

Though the duration varied, females that wintered on the south side of the Alaska Peninsula spent almost twice as many days at wintering sites as birds in the western Aleutian Islands. Emperor geese that winter on the Alaska Peninsula have a shorter migration than Aleutian migrants, but are at higher latitudes, where they experience colder winter temperatures and shorter days. Thus, there could be a tradeoff between migration and winter energetic costs. Mean January temperature was $-3.3^{\circ} \mathrm{C}$ at Chignik, a central location on the south side of the Alaska Peninsula, whereas it was $0.6^{\circ} \mathrm{C}$ at Adak in the western Aleutian Islands. We do not know whether there are regional differences in forage availability. Rather than building endogenous reserves for migration to more distant wintering sites, emperor geese that winter on the Alaska Peninsula may need to build reserves in autumn to carry them through periods of subfreezing temperature and short days in winter. Mason et al. (2006) noted that Pacific black brant that wintered on the Alaska Peninsula employed such a strategy and entered winter with larger lipid deposits than brant that migrated to and wintered in Mexico.

Spring migration from wintering areas to coastal lagoons on the Alaska Peninsula was similar to fall migration in that it was rapid and we observed little evidence that geese regularly used intermediate stopovers. We again observed some migrants from the western Aleutian Islands using oceanic migration routes. In order to meet migration costs, emperor geese that winter in the Aleutian Islands likely increase endogenous reserves before leaving their winter sites in a manner similar to that observed in Pacific black brant (Mason et al., 2006), greater white-fronted geese (Anser albifrons; Ely and Raveling, 1989), and Canada geese (Branta canadensis; Raveling, 1979).
In spring, many emperor geese returned to the same primary staging area on the Alaska Peninsula that they had used in the fall, and birds that remained on staging areas longer in spring had spent more days staging the previous fall. Thus, fidelity to staging habitats influenced spatial and temporal distribution of emperor geese among staging areas. Spring staging was likely important to birds not only to increase reserves before migration to the $\mathrm{YKD}$, but also to prepare physiologically for reproduction. Schmutz et al. (2006) observed that the protein reserves available to female emperor geese during incubation, as well as approximately $50 \%$ of the protein that these females invested in egg yolks, were derived from marine environments, likely Alaska Peninsula staging areas.

Spring conditions on staging areas may influence timing of reproduction on the YKD. We observed earlier departure from the Alaska Peninsula in 2003 and 2004 compared to 2000. In 2000, Port Heiden had 16 days with mean temperatures below freezing between 1 April and 10 May, compared to one day during the same interval in 2003 and five days in 2004 (National Climatic Data Center, 2006). Nest initiation on the YKD was earlier in the warmer springs, and there was evidence that in those years some females initiated rapid follicle development while on staging areas, which resulted in a shorter prelaying interval after arrival at the nesting area compared to 2000 (Hupp et al., 2006a). Because spring temperatures on the Alaska Peninsula are highly correlated to those on the YKD (Hupp et al., 2006a), conditions on spring staging areas likely provide emperor geese with cues of when to initiate migration to the YKD (Petersen, 1992) and whether to initiate follicle development prior to departure.

Distribution of emperor geese and timing of their movements from the Alaska Peninsula could affect population estimates that are derived from spring aerial surveys of coastal areas of the YKD, Bristol Bay, and Alaska Peninsula. Surveys are typically conducted during late April and early May. In 2000 and 2003, 19 of 21 emperor geese (90\%) were in areas where they could have been detected during spring surveys. In 2004, however, only 11 of 15 females with PTTs (73\%) were located in survey areas. The remaining four females in 2004 would not have been detected because they were in transit between the Alaska Peninsula and the YKD at the time that surveys were conducted. The spring population index for emperor geese in that year was $24 \%$ lower than for $2000,34 \%$ lower than for 2003, and $25 \%$ lower than the long-term average (Dau and Mallek, 2004). The lower count in 2004 was likely due in part to the timing of the survey, which took place while many birds were migrating. If surveys can be completed before April 30, they will be more apt to detect emperor geese before birds have initiated migration from the Alaska Peninsula.

Eisenhauer and Kirkpatrick (1977) suggested that emperor geese migrated northward among Alaska Peninsula staging areas and crossed Bristol Bay at Egegik. Although we observed some northward movement among lagoons, most emperor geese departed from the central staging 
areas (Nelson Lagoon, Seal Islands, Port Heiden) when crossing Bristol Bay. This observation is consistent with those of Petersen and Gill (1982). An emperor goose that migrates directly from Nelson Lagoon to the YKD would reduce flight distance by approximately $300 \mathrm{~km}$ compared to one that migrates to Egegik Bay before crossing Bristol Bay. Although we observed little evidence that emperor geese used stopover sites between the Alaska Peninsula and the YKD, they can concentrate along the north coast of Bristol Bay in years when snowmelt is delayed on the YKD (Eisenhauer and Kirkpatrick, 1977).

We conclude that chronology of migration and use of staging and winter habitats were influenced by the distance emperor geese migrated between nesting and winter sites. Short-distance migrants used fall staging areas less, but they remained on winter sites longer than birds that migrated greater distances. Emperor geese that nested sympatrically employed different migration strategies, yet their arrival dates and reproductive effort after arrival on the YKD were not influenced by the distance they had migrated (Hupp et al., 2006a). That may have been possible because staging areas on the Alaska Peninsula enabled emperor geese from different winter regions to reach comparable levels of condition before nesting. Alaska Peninsula staging areas were especially important to emperor geese because over $86 \%$ of the population was concentrated in a total area of approximately $1100 \mathrm{~km}^{2}$ (Hupp et al., 2007b) for four to five months of the year. Females that wintered in the western Aleutian Islands typically spent more of their annual cycle on staging areas than at winter or summer habitats. The availability of highquality feeding habitat in isolated coastal lagoons where human disturbance was minimal likely contributed to high survival rates of emperor geese during staging and winter (Hupp et al., 2007b). Although emperor geese spent most of their staging periods at a single lagoon, many moved among lagoons, especially during arrival at, and departure from, the Alaska Peninsula. Thus the coastal lagoons on the Alaska Peninsula functioned as a network of staging areas. Maintenance of the complete network is necessary to ensure that emperor geese can prepare for the energetic and nutritional demands of migration and reproduction. Because there was no evidence of population division outside of the YKD, events that affect emperor geese on staging or winter areas would likely affect all components of the nesting population.

\section{ACKNOWLEDGEMENTS}

This project was sponsored by the U.S. Geological Survey, Alaska Science Center. We received considerable support from the Yukon Delta, Togiak, Alaska Peninsula, Izembek, and Alaska Maritime national wildlife refuges, as well as the Alaska Region of Migratory Bird Management, U.S. Fish and Wildlife Service. Special thanks to the numerous biologists from the Alaska Science Center who assisted with capture and marking of geese. D. Mulcahy,
K. Burek, C. Stewart, and T. Kelly served as veterinarians, and P. Busteed, P. Fontaine, D. Mason, and M. Shepherd were anesthetists during implantation of transmitters. D. Douglas provided much assistance with collection and analysis of satellite telemetry data. We are grateful to F. Broerman, P. Leidberg, J. Morgart, M. Rearden, and G. Walters with the Yukon Delta National Wildlife Refuge for their support of the study. C. Dau provided input throughout the project. Our thanks to D. Derksen for his support. We appreciate reviews of the manuscript by C. Dau, J. Fischer, S. Johnson, and two anonymous referees.

\section{REFERENCES}

ALERSTAM, T., and LINDSTRÖM, Å. 1990. Optimal bird migration: The relative importance of time, energy, and safety. In: Gwinner, E., ed. Bird migration. Berlin: Springer-Verlag. $331-351$.

BALDASSARRE, G.A., and BOLEN, E.G. 2006. Waterfowl ecology and management, 2nd ed. Malabar, Florida: Krieger Publishing Company.

BÉCHET, A., GIROUX, J.-F., GAUTHIER, G., NICHOLS, J.D., and HINES, J. 2003. Spring hunting changes the regional movements of migrating greater snow geese. Journal of Applied Ecology 40:553-564.

BLEM, C.R. 1976. Patterns of lipid storage and utilization in birds. American Zoologist 16:671-684.

BURNHAM, K.P., and ANDERSON, D.R. 2002. Model selection and multimodel inference: A practical information-theoretic approach, 2nd ed. New York: Springer-Verlag.

DAU, C.P. 1992. The fall migration of Pacific Flyway brent Branta bernicla in relation to climatic conditions. Wildfowl 43:80-95.

DAU, C.P., and MALLEK, E.J. 2004. Aerial survey of emperor geese and other waterbirds in southwestern Alaska, spring 2004. Unpubl. ms. Available at the U.S. Fish and Wildlife Service, 1011 E. Tudor Road, Anchorage, Alaska 99503.

DOUGLAS, D. 2006. The Douglas Argos-Filter Algorithm. Anchorage, Alaska: U.S. Geological Survey, Alaska Science Center. http://alaska.usgs.gov/science/biology/spatial/ douglas.html.

EISENHAUER, D.I., and KIRKPATRICK, C.M. 1977. Ecology of the emperor goose in Alaska. Wildlife Monographs 57:1-62.

ELY, C.R., and RAVELING, D.G. 1989. Body composition and weight dynamics of wintering greater white-fronted geese. Journal of Wildlife Management 53:80-87.

ELY, C.R., and TERENZI, J. 2003. Nesting ecology of geese along the Kashunuk River, Yukon-Kuskokwim Delta, Alaska. Unpubl. ms. Available at the Alaska Science Center, 1011 E. Tudor Road, Anchorage, Alaska 99503.

FREDERICK, R.B., and KLAAS, E.E. 1982. Resource use and behavior of migrating snow geese. Journal of Wildlife Management 46:601-614.

HARRIS, R.B., FANCY, S.G., DOUGLAS, D.C., GARNER, G.W., AMSTRUP, S.C., McCABE, T.R., and PANK, L.F. 1990. Tracking wildlife by satellite: Current systems and performance. Technical Report 30. Washington, D.C.: U.S. Fish and Wildlife Service. 
HESTBECK, J.B., NICHOLS, J.D., and MALECKI, R.A. 1991. Estimates of movement and site fidelity using mark-resight data of wintering Canada geese. Ecology 72:523-533.

HUPP, J.W., SCHMUTZ, J.A., and ELY, C.R. 2006a. The prelaying interval of emperor geese on the Yukon-Kuskokwim Delta, Alaska. Condor 108:912-924.

HUPP, J.W., PEARCE, J.M., MULCAHY, D.M., and MILLER, D.A. 2006b. Effects of abdominally implanted radio transmitters with percutaneous antennas on migration, reproduction, and survival of Canada geese. Journal of Wildlife Management 70:812-822.

HUPP, J.W., SCHMUTZ, J.A., ELY, C.R., SYROECHKOVSKIY, E.E., Jr., KONDRATYEV, A.V., ELDRIDGE, W.D., and LAPPO, E. 2007a. Moult migration of emperor geese Chen canagica between Alaska and Russia. Journal of Avian Biology 38(4):462-470, doi:10.1111/j.2007.0908-8857.03969.x.

HUPP, J.W., SCHMUTZ, J.A., and ELY, C.R. 2007b. Migration, winter distribution, and prelaying intervals of emperor geese, final report. Unpubl. ms. Available at the Alaska Science Center, 1011 E. Tudor Road, Anchorage, Alaska 99503.

KORSCHGEN, C.E., KENOW, K.P., GENDRON-FITZPATRICK, A., GREEN, W.L., and DEIN, F.J. 1996. Implanting intra-abdominal radio-transmitters with external whip antennas in ducks. Journal of Wildlife Management 60:132-137.

MADSEN, J. 1998. Experimental refuges for migratory waterfowl in Danish wetlands. II. Tests of hunting disturbance effects. Journal of Applied Ecology 35:398-417.

MASON, D.D., BARBOZA, P.S., and WARD, D.H. 2006. Nutritional condition of Pacific black brant wintering at the extremes of their range. Condor 108:678-690.

NATIONAL CLIMATIC DATA CENTER. 2006. Integrated surface hourly data, Alaska. http://lwf.ncdc.noaa.gov/oa/ ncdc.html.

PACIFIC FLYWAY COUNCIL. 2006. Draft Pacific Flyway management plan for the emperor goose. Portland, Oregon: Emperor Goose Subcommittee, Pacific Flyway Study Committee, U.S. Fish and Wildlife Service.
PETERSEN, M.R. 1983. Observations of emperor geese feeding at Nelson Lagoon, Alaska. Condor 85:367-368. 1992. Reproductive ecology of emperor geese: Annual and individual variation in nesting. Condor 94:383-397.

PETERSEN, M.R., and GILL, R.E., Jr. 1982. Population and status of emperor geese along the north side of the Alaska Peninsula. Wildfowl 33:31-38.

PETERSEN, M.R., SCHMUTZ, J.A., and ROCKWELL, R.F. 1994. Emperor goose (Chen canagica). In: Poole, A., and Gill, F., eds. The birds of North America, No. 97. Philadelphia, Pennsylvania: The Academy of Natural Sciences and Washington, D.C.: The American Ornithologists' Union.

RAVELING, D.G. 1979. The annual cycle of body composition of Canada geese with special reference to the control of reproduction. Auk 96:234-252.

REED, A., STEHN, R., and WARD, D. 1989. Autumn use of Izembek Lagoon, Alaska by brant from different breeding areas. Journal of Wildlife Management 53:720-725.

ROBERTSON, G.J., and COOKE, F. 1999. Winter philopatry in migratory waterfowl. Auk 116:20-34.

SAS INSTITUTE INC. 1990. SAS/STAT user's guide. Version 6, 4th ed. Cary, North Carolina: SAS Institute Inc.

SCHMUTZ, J.A. 1993. Survival and pre-fledging body mass in juvenile emperor geese. Condor 95:222-225.

-1994. Age, habitat and tide effects on feeding activity of emperor geese during autumn migration. Condor 96:46-51.

SCHMUTZ, J.A., HOBSON, K.A., and MORSE, J.A. 2006. An isotopic assessment of protein from diet and endogenous stores: Effects on egg production and incubation behavior of geese. Ardea 94:385-397.

U.S. FISH AND WILDLIFE SERVICE. 2005. Waterfowl population status, 2005. Washington, D.C.: U.S. Department of the Interior. http://migratorybirds.fws.gov/reports/status05/ final_status_05.pdf

ZAR, J.H. 1984. Biostatistical analysis, 2nd ed. Englewood Cliffs, New Jersey: Prentice-Hall, Inc. 